\title{
AGENDA JURÍDICO-POLÍTICA \\ DEL MERCOSUR. TENDENCIAS
}

\section{AGENDA JURÍDICO-POLÍTICA DO MERCOSUL. TENDENCIAS}

Rita Gajate*

Resumen: Numerosos debates presentes tienen como objeto de discusión la orientación que tomará el MERCOSUR a más de veinte años de su creación y en su actual coyuntura. Es que la encrucijada entre profundización y ampliación del bloque no se encuentra resuelta. Si se centra la visión en la alternativa de su profundización se advierte que la tendencia parecería priorizar los pendientes en el área política y social: la necesidad de garantizar el orden democrático, fortalecer la participación y propender a la constitución de una ciudadanía que sustente la legitimación del proceso de integración.

Individualizadas las consistencias/inconsistencias de la actual estructura institucional del MERCOSUR (Gajate: 2012), nos preguntamos si el bloque está en condiciones de abordar la ambiciosa agenda jurídico - política que se propone acentuar y donde se encuentran sus fortalezas y debilidades para llevarla a cabo.

Resumo: Numerosos debates na atualidade têm como objeto de discussão a orientação que tomará o MERCOSUL aos mais de vinte anos de sua criação e em sua atual conjuntura. Isso se deve ao fato de a encruzilhada entre seu aprofundamento e ampliação não se encontrar resolvida. Caso seu foco se concentre na alternativa do aprofundamento, é de se advertir parecer haver tendência a se priorizar as pendências nas

Profesora Adjunta Ordinaria de Economía Política, Facultad de Ciencias Jurídicas y Sociales UNLP. Profesora de Derecho de la Integración en la Maestría en Integración Latinoamericana y Especialización en Políticas de Integración, Facultad de Ciencias Jurídicas y Sociales, Universidad Nacional de La Plata. Profesora Adjunta Ordinaria de Economía Política, Universidad Nacional del Noroeste de la Provincia de Buenos Aires.

Abogada. Mediadora. Especialista en Integración Latinoamericana. Investigadora Categorizada II, Ministerio de Educación, Ciencia y Tecnología de la República Argentina.

Profesora visitante de la "Indianápolis School of Law", Indianápolis. Profesora visitante de las Universidades "Leopold Franzes" de Innsbruck, Austria y "Pompeu Fabra" de Barcelona, España.

Secretaria de Asuntos Académicos de la Facultad de Ciencias Jurídicas y Sociales de la Universidad Nacional de La Plata. Períodos: 2007-2010 / 2010-2012.

Actualmente Secretaria de la Cámara de Apelaciones Civil y Comercial, Sala I del Departamento Judicial La Plata. 
áreas política e social: a necessidade de garantir a ordem democrática, fortalecer a participação e tender à constituição de uma cidadania que sustente a legitimação do processo de integração. Individualizadas as consistências/inconsistências da atual estrutura institucional do MERCOSUL (Gajate: 2012), perguntamos-nos se o bloco está em condições de abordar a ambiciosa agenda jurídico-politica que se propõe acentuar e onde se encontram suas fortalezas e debilidades para levá-la a cabo.

Palabrasclave: MERCOSUR, Agendajurídico-política,Institucionalidad, Ciudadanía

Palavras-chave: MERCOSUL, Agendajurídico-política, Institucionalidade, Cidadania

\section{Presentación}

El MERCOSUR se enfrenta a nuevos escenarios de ampliación y profundización. Las solicitudes de Ecuador y Bolivia para su inclusión como miembros plenos suman incertidumbre acerca de los nuevos rumbos que tomará este grupo integrado.

Ad intra, el bloque se propone la profundización del proceso que parecería orientarse hacia el desarrollo de una agenda político-jurídica que recoge una demanda social de mayor protagonismo, construcción de una ciudadanía común e institucionalización de la participación democrática.

La evolución del MERCOSUR en su orientación y contenidos constituye uno de los temas de debate que se plantean en la sociedad, en la medida que revelan cuestiones sensibles que atraviesan el espectro político y sectorial y se colocan en el escenario posibles modelos de desarrollo humano y proyección del bloque en el sistema regional e internacional (Bizzózero, 2011).

La adopción de una agenda en torno a prioridades políticas implica necesariamente un análisis jurídico-institucional para superar el riesgo de la retórica adolescente de instrumentos aptos para lograr objetivos. Por esta razón se visualiza como pertinente indagar acerca de las fortalezas y debilidades jurídico-institucionales del MERCOSUR para enfrentar sus perspectivas políticas.

En un marco de tensión, las conclusiones de la XLV Cumbre del MERCOSUR realizada en Montevideo -recientemente y sobre el cierre 
del presente trabajo-, confirman la tendencia a la acentuación política de la agenda del bloque. La observación de lo ocurrido revela que el movimiento político define el clima de su avance y temáticas tratadas. El cese de la suspensión de Paraguay, el ingreso de Bolivia como socio pleno, la futura adhesión de Guyana y Surinam y las declaraciones en torno al reconocimiento universal del Derecho de Asilo Político, han determinado las directrices de los próximos pasos en la región.

Asimismo, y a través de la posición de la República Oriental del Uruguay, expresada en la propuesta de su primer mandatario, se hace imperiosa la toma de posición frente la necesidad de fijar un Arancel Externo Común en el bloque para contener la entrada de productos chinos a la región y proteger la industria local. Es que el considerado gigante asiático viene ganando presencia comercial en Sudamérica. El avance de la Alianza del Pacífico que representa el $35 \%$ del PBI latinoamericano y el $55 \%$ de las exportaciones de la región al resto del mundo (IADE, 2013) también representa un desafío político de dimensiones considerables para el MERCOSUR.

A este panorama se suman los problemas entre los dos socios mayores del bloque, que se han multiplicado en los últimos tiempos en los campos del comercio y las inversiones, lo que también roza la relación con Uruguay (Revista Mercado, 2013). Un tema bilateral de importancia clave que debería ser resuelto durante agosto es la renovación del acuerdo automotor que actualmente se encuentra vencido.

Asimismo se ha confirmado la tendencia que demuestra que los temas donde se ha logrado mayor consenso son los de la agenda social, educativa y de salud, mientras que las problemáticas comerciales han quedado relativamente relegadas esta vez.

El panorama descripto justifica la reflexión sobre las tendencias en los nuevos rumbos del MERCOSUR.

\section{Actualidad y perspectivas del MERCOSUR. Su agenda jurídico - política}

El giro que este proceso de integración toma en la actualidad se explica desde su evolución y se justifica en su proyección. Desde la perspectiva evolutiva se ha afirmado que el hilo conductor en veinte años de desarrollo ha sido la definición de un marco de desarrollo institucional y cualificación de los costos y los beneficios de su sostenimiento para asegurar la adhesión continua de sus miembros y consolidar los procesos transitados. En cuanto a su proyección se 
advierte un cambio de rumbo que ha sido enunciado en ambiciosos objetivos dispuestos al corto y mediano plazo constituyendo un nuevo interrogante su dotación institucional y organizacional para dar respuesta a las iniciativas planteadas. Destacados doctrinarios abonan este diagnóstico.

Si bien el Tratado de Asunción es producto del nuevo dinamismo integrador de comienzos de la década del 90 y se inserta en la concepción del regionalismo abierto; se ha constituido -asimismocomo un instrumento para la consolidación democrática en el cono sur. Nuestros países han garantizado en estas últimas décadas los principios jurídicos propios del Estado de derecho en dichas iniciativas, aunque en la actualidad se revele un cierto debilitamiento de sus instituciones.

Así, desde la primera perspectiva arriba definida, la Asociación Latinoamericana de Organizaciones de Promoción al Desarrollo (ALOP, 2011) se afirma que en lo que hace a la cuestión jurídica en el MERCOSUR, es preciso indicar que se registraron en el último lustro intentos por solucionar la hipertrofia de normas emanadas de los órganos decisorios y que no son aplicables en los países por no haber entrado en vigor, ya que requieren internación. No obstante estos esfuerzos, prevalece la opacidad y la falta de interpretación uniforme del derecho derivado en todo el bloque, lo que ha erosionado la credibilidad interna y externa del MERCOSUR durante el período. En cuanto a su dimensión político-ideológica del proceso es posible indicar que el MERCOSUR se ha constituido como una zona de paz, que ha propulsado el mantenimiento y profundización del Estado de derecho a través de la sanción y aplicación de la Cláusula Democrática entre los países del bloque y sus asociados. Por otra parte, se visualiza que aún no existen alianzas políticas transnacionales, sin embargo ha de esperarse que con el Parlamento ello camine en esa dirección. En cuanto a la cuestión de la afinidad ideológica observada desde 2003 en la región, se pudo inferir que permitió profundizar el proceso a través de la introducción de un discurso y algunos mecanismos de justicia y participación social, todavía muy tímidos. Está pendiente avanzar sobre una institucionalidad acorde a un modelo de integración progresista.

En la investigación de Lincoln Bizzózero (2011), desde el análisis de la articulación nacional - regional se concluye que se evidencia el cambio de perspectiva señalado en el bloque.

Coincidiendo sobre este piso de marcha Gerardo Caetano (2011) sostiene que en un balance histórico de este proceso dinámico y cambiante de dos décadas, no parece creíble un proyecto de profundización del 
MERCOSUR sin una inflexión de sinceramiento profundo entre sus Estados Partes, a los efectos de renovar el pacto "para andar juntos" de cara a los nuevos contextos. Pero desde esa premisa ineludible, ¿cuál podría ser el listado sucinto de los titulares de esa agenda de profundización para el MERCOSUR a sus veinte años? Como se verá, no se trata tanto de agregar temas novedosos sino de confirmar y consolidar un programa sobre el que ya existe una masa crítica razonable. Una pequeña reseña de aspectos sustantivos de ese programa de profundización se presenta como ineludible: complementación productiva, a través de los Foros de Competitividad y del surgimiento de cadenas productivas mercosureñas; complementación de políticas de proyección regional (energéticas, educativas, culturales, de derechos humanos); complementación y creación de infraestructuras comunes; coordinación macroeconómica, en particular, de las políticas cambiarias; consolidación y aplicación efectiva de la Carta Socio Laboral; tratamiento serio de la propuesta ya acordada de libre circulación de personas; reconocimiento de asimetrías y flexibilidades legítimas, en especial en relación a Paraguay y Uruguay; implementación plena e incremental de los Fondos de Convergencia Estructural del MERCOSUR (FOCEM); negociación internacional como bloque económico-comercial y también político ante terceros y en foros internacionales; estrategia comercial conjunta; estrategias de financiamiento intrazona; incorporación consistente de nuevos socios. Para todo lo cual es indispensable una nueva institucionalidad que sea funcional a los objetivos referidos.

En sentido concordante otros trabajos de importante valía fueron dados a luz en los últimos años: Arrosa Soares (2011), Bauman Renato (2011), Mellado (2011 y 2012).

Desde la perspectiva de una de las líneas de investigación del Instituto de Integración de la Universidad Nacional de La Plata, hemos sostenido que el análisis de la dimensión jurídica de la integración implica considerar la morfología institucional, su funcionalidad, su consistencia estructural y su coherencia ideológica en relación al modelo adoptado. Es así como el Derecho se constituye como un instrumento del que la actividad política se vale para organizar la sociedad en un lugar y tiempo dado. Este instrumento, refleja claramente los lineamientos políticos de la clase gobernante. De este modo las nociones de soberanía e independencia de cada estado partícipe, delegación de competencias, representatividad, participación, sustentabilidad jurídica y gobernabilidad se abren paso en las configuraciones jurídico - institucionales que se adoptan.

Es que la institucionalidad de un sistema expresa la adopción de 
un modelo que lo conforma (Gajate, 2011). Manifiesta el modo que se espera en el funcionamiento y evolución del esquema. Es que la problemática institucional ha de entenderse como una de las dimensiones configurantes de un sistema complejo multidimensional. Este es nuestro punto de partida: la observación de las mutuas implicancias entre las ideas políticas subyacentes y las decisiones institucionales adoptadas.

La coordinación de las macropolíticas en este estadío del proceso de integración se torna indispensable para que el conjunto avance sus diversos niveles de interacción.

La orientación y formulación de políticas deriva directamente en el universo de la creación jurídica, es más: esta es su expresión. Por esta razón nos proponemos reflexionar sobre el modo en que impactan estas definiciones en la creación de instituciones en el MERCOSUR y si las ya creadas constituyen instrumentos aptos para la realización de los objetivos propuestos en la actual agenda.

\section{Interacciones entre Ciencia Política y Ciencias Jurídicas}

La Resolución del GMC 20/92, que creó la Comisión de Política MonLa Ciencia Política enfrenta hoy el desafío de recuperar el sentido universal de su objeto de estudio y devolverle así el carácter de ciencia de fundamentación que aspira a elucidar lo global político en un proceso sinóptico-integrativo bajo la atracción recíproca de las ciencias singulares que la conciernen (Pantoja, 1988).

Con el advenimiento de la sociedad moderna la Ciencia Política abre paso a modernas disciplinas especializadas que tratan de explicar el fenómeno político desde sus propios ángulos y sirviéndose de sus propios métodos ya que un pensamiento de separación positivista aparece como la más elevada expresión de lo científico. Se entendió que se trataba de demostrar la pureza de la ciencia mediante la particularidad de los correspondientes métodos de cada eventual disciplina: así, de este modo el método determinó el objeto y no al revés y las ciencias fincaron su orgullo de afirmarse como disciplinas inconfundiblemente independientes. Es así como la ciencia política se convirtió en la suma de las ciencias especializadas, ante las que, finalmente, ella misma se organizó como ciencia autónoma (Sontheimer Kurt, 1971).

El derecho moderno, a diferencia de las ordenaciones normativas anteriores, se caracteriza por ser un derecho igualitario para los hombres independientemente de sus condiciones particulares. La ley aparece como la voluntad del Estado, el lugar donde se encuentra concentrado 
el interés general y no los intereses particulares, pues es adoptada por los representantes de ese interés general, quienes se expresan en nombre de la nación por la ley y el derecho, que se consideran entonces expresiones de la voluntad general. Se oculta así lo genérico, la voluntad de la clase hegemónica, toda vez que depende de la estructura social $\mathrm{y}$ no de individuos que forman parte de una clase, el que su voluntad dominante adopte la forma de ley (Córdova Arnaldo, 1967). Por esta razón su contenido político y social no puede soslayarse de los estudios que intentan explicar los fenómenos jurídicos configurativos.

No obstante es herencia de Hans Kelsen el pensamiento que sostiene hasta las últimas consecuencias que la teoría de que si el Estado no es más que la personificación del derecho, puesto que el estado es un orden jurídico relativamente centralizado, entonces la soberanía, el poder de poderes, corresponden al ámbito explicativo exclusivo del derecho (Kelsen, 1965).

Los diálogos entre Ciencia Política y Derecho se presentan como superadores en la epistemología actual y se producen a partir de la necesidad de una mejor comprensión de los fenómenos sociales actuales. Es por tal razón que la evolución de esta línea de pensamiento confluye en la idea de que si bien el Derecho logra su emancipación científica ante la filosofía y otras ciencias sociales, afirmándose como disciplina autónoma en los siglos XIX y XX, esto no implica que se convierta en una teoría autónoma de normas sino que su análisis debe necesariamente provocar una conexión con otras ramas de las Ciencias Sociales mediante la identificación de su incidencia sustancial en un mismo terreno, que es el de las relaciones sociales (Cerroni, 1972).

Por las explicitadas razones teóricas abordaremos nuestro objeto de estudio desde el análisis jurídico - político identificando el impacto de la adopción de una nueva agenda política para el MERCOSUR y la generación de instituciones destinadas a concretarla.

\section{El MERCOSUR jurídico - político}

El MERCOSUR nació de la confluencia de las voluntades políticas de los gobiernos de Argentina y Brasil a la que se sumaron desde su origen, Paraguay y Uruguay. Si bien el Tratado de Asunción que le dio vida no incluyó previsiones sobre la dimensión del diálogo político, éste se fue abriendo camino como consecuencia de las afinidades históricas y culturales entre los países de la región; los cuales también comparten en gran medida la perspectiva desde la que observan la evolución del proceso de globalización, sus riesgos y sus oportunidades. 
De este modo, el MERCOSUR político es el resultado de la decisión de sus Estados Miembros de afianzar la percepción del proceso regional como abarcador de todas las dimensiones de la integración con el propósito de lograr la consolidación política del MERCOSUR, profundizarlo en las áreas de desarrollo social, de educación, de cultura, de seguridad y justicia, y estimular en los habitantes de la región la conciencia de pertenecer a un espacio común (Ueltschi, 2003).

La conformación de ese espacio común es paulatina, pues el actual ordenamiento jurídico e institucional del MERCOSUR -al carecer de una expresión supranacional- no permite, por el momento, establecer políticas comunes en ámbitos que trasciendan lo económicocomercial. No obstante, se procura generar un intercambio de ideas y una coordinación de posiciones entre los referentes de los diversos ámbitos de gobierno de los Estados Partes y países asociados.

En este sentido, la participación decidida de los presidentes ha sido fundamental: su activa presencia en las Cumbres semestrales permitió inyectar contenido político a un proceso de decisión que quizás hubiera tenido otro resultado, si hubiera quedado librado exclusivamente a criterios técnicos y económicos (Mellado, 2011).

Asimismo, la dimensión política del MERCOSUR tiende a consolidar la presencia del bloque regional como un actor definido en la escena internacional y con una posición propia ante situaciones que afecten directa o indirectamente a la subregión.

Del 2003 a la actualidad han tenido lugar una serie de avances político-institucionales que dan cuenta de que el proceso de integración regional atraviesa tiempos de cambio. La creación y fortalecimiento de instituciones como el Parlamento del MERCOSUR, el Instituto Social del MERCOSUR, el Instituto de Formación del MERCOSUR, el Foro Consultivo Económico y Social, entre otros, son expresión de que la decisión de institucionalizar alguno de los aspectos que hacen a la integración política y social del MERCOSUR. Se observa, no obstante, que la integración político-social tiene aún desafíos a nivel estructural, es decir en la instrumentalización de estas políticas (FLACSO, 2009).

Este déficit señalado ha sido denominado como "déficit transversal de densidad social" (Rodríguez Tania, 2009) significando que las instituciones creadas son importantes pero insuficientes para masificar las políticas del bloque en las sociedades de los Estados parte.

El desarrollo del bloque y la reciente decisión de impulsar la 
Agenda jurídico-política del MERCOSUR. Tendencias. Rita Gajate

integración en dimensiones no comerciales han hecho visible la problemática de un déficit en cuanto a rendición de cuentas del MERCOSUR para con la sociedad y sus actores políticos y sociales. Dicha carencia está vinculada, entre otras cosas, a que la representación política en el MERCOSUR, se encuentra concentrada en los poderes ejecutivos nacionales y, a su vez, a la inexistencia de una política de comunicación y difusión de la información, a pesar de lo reflejado en la prensa (CTA Secretaría de RRII, 2006).

La integración, no es un proceso exclusivamente económico, intergubernamental o interestatal. Por el contrario, necesita el concurso activo de los actores políticos y de la sociedad civil para adquirir vigencia en el marco del sistema de principios y valores aceptados por las democracias contemporáneas. La participación de la ciudadanía en el proceso de integración es un factor de legitimidad y una condición de éxito. Si sólo participan los gobiernos, el proceso se estanca y fracasa.

En este sentido, la consideración de una representación de los ciudadanos en los parlamentos suramericanos, implica un avance en la opción por legitimar las decisiones de la integración con una base poblacional. De allí que la elección directa y universal de los parlamentarios deviene una necesidad para todos y de cada uno de los Estados, como una demostración de la voluntad de cumplimiento de sus compromisos y obligaciones internacionales consensuadas en el marco de la institucionalización creciente en los esquemas vigentes.

El déficit democrático que padecen los procesos de integración suramericanos radica en la concentración de poder en los órganos intergubernamentales y en la reducción de funciones y autonomía de los órganos de carácter comunitario. Muestra de ello, es que tanto el Parlamento Andino como el PARLASUR, a pesar de ser órganos fundamentales que deberían generar el involucramiento de la sociedad civil, tienen -hasta el presente- una función básicamente declarativa y deliberativa sin ningún poder decisorio y de carácter realmente vinculante (Alvarado, 2011 y 2011a).

La no superación del déficit democrático que a la fecha, se observa en los procesos de integración suramericanos radica en que aún los ejecutivos de los Estados absorben todas las atribuciones de gestión del proceso de integración, ejerciéndolas en virtud de su competencia de manejar las relaciones internacionales. En otras palabras, se aprecia que dentro del contexto de los Estados se presenta una gran concentración en las autoridades ejecutivas del proceso integracionista, tanto para diseñar políticas, implementarlas y ejercer el control de su aplicación, como en 
razón a la debilidad de un ente fiscalizador que garantice su adecuada ejecución. Esta última función debe ser realizada por un órgano autónomo, fuerte, con capacidad vinculante en sus pronunciamientos, y que garantice la debida aplicación de las directrices integracionistas, lo cual sólo podrá darse cuando los Parlamentos gocen de la legitimidad que le otorgue tener miembros designados por vía de elección popular.

\section{El rol del Parlamento del MERCOSUR en el avance de la agenda política}

El Parlamento del MERCOSUR se ha configurado como el órgano de representación de la pluralidad ideológica y política de los pueblos de los países miembros del MERCOSUR. Fue creado el 9 de diciembre de 2005 por CMC 23/05 y comenzó a funcionar el 7 de mayo de 2007.

Sobre la base de la conformación de la Comisión Parlamentaria Conjunta-CPC-, en una primera etapa, sus miembros fueron elegidos por los parlamentos nacionales de entre sus cuadros, y en su etapa definitiva será elegido por voto directo de los ciudadanos siguiendo el criterio de representatividad ciudadana.

La creación del Parlamento del MERCOSUR es parte de un proceso abierto en 2002, de constitución de organismos y procedimientos que tienen como fin evidente institucionalizar el bloque y darle permanencia y autonomía política.

En ocasión de la XXVII Cumbre de Presidentes de Ouro Preto, el 17 de diciembre de 2004, el Consejo del Mercado Común encomendó a la CPC la redacción de una propuesta de Protocolo Constitutivo del Parlamento del MERCOSUR, con el mandato de entregar la misma antes de la finalización de 2006.

La CPC realizó el proyecto con antelación a la fecha de vencimiento y el 9 de diciembre de 2005, los presidentes de Argentina, Brasil, Paraguay y Uruguay, firmaron el Protocolo Constitutivo del Parlamento del MERCOSUR constituyendo el nuevo organismo. El Parlamento de MERCOSUR debía comenzar a funcionar antes del 31 de diciembre de 2006, pero finalmente concretó su primer reunión el 7 de mayo de 2007, dejando de existir la Comisión Parlamentaria Conjunta. En el mes de junio de 2008, se reunieron por primera vez fuera de Montevideo, en la ciudad de San Miguel de Tucumán, en conjunto con la XXXV Cumbre del MERCOSUR, realizada también en esa ciudad argentina. La creación de este órgano actualiza el debate "parlamentarismo versus presidencialismo" que despunta en América Latina a mediados de los 
años ochenta, cuando varios países de la región entraban en el proceso de transición y salida de sus regímenes autoritarios hacia la configuración de sus democracias. Dicho debate continúa enriqueciéndose con una visión más compleja del mismo en la que impactan diversos factores en su caracterización.

Introduciéndonos en un análisis político del MERCOSUR, hemos de afirmar que la consolidación democrática del bloque ha partido de un proceso intergubernamental cuyo avance ha sido influenciado por dos tipos de factores: los de carácter exógeno y endógeno. Los primeros comprenden las políticas económicas, las políticas exteriores y las dinámicas políticas internas de cada Estado miembro; los segundos se refieren a los aspectos institucional-burocráticos, socioeconómicos y político-ideológicos vinculados a los procesos de integración regional. Sin embargo, dado que el eje Argentina-Brasil constituye el núcleo político del proceso asociativo, el peso de los factores señalados, particularmente los de carácter exógeno, no será igual para todos los Estados miembros (Puelles Benítez - Urzúa Fraderman, 2011).

Gerardo Caetano (2006:32) demuestrael modo en queestos factores han influido para que la evolución del Parlamento del MERCOSUR no fuera abrupta, sino que recorriera una extensa trayectoria signada por los principios clásicos de gradualidad, flexibilidad y equilibrio. Con dicho argumento prueba que el debate por la institucionalización de una participación efectiva de los Legislativos de los Estados parte del MERCOSUR en la formulación de políticas de comercio exterior, no ha sido pacífico ni sencillo.

Podría afirmarse que si por más un lustro los dirigentes no encontraron la confirmación deseada, este hecho puede evidenciar precisamente la existencia de diferencias y distintas sensibilidades ante la iniciativa de institucionalizar un Parlamento del MERCOSUR.

Sin embargo el Parlamento del MERCOSUR parece que prosperara como una gran expectativa en relación a su dimensión política. El reforzamiento de esta dimensión de órgano político por excelencia, indica que este aspecto está en el corazón mismo del proyecto de creación de un Parlamento regional. Refiere también a la posibilidad de configurarse como una usina de propuestas integracionistas, traducidas en declaraciones, recomendaciones e informes sobre diversas cuestiones (Ídem).

El mismo autor citado expresa que, sin versiones dramáticas ni apocalípticas, desde una fuerte y probada definición a favor del 
MERCOSUR como horizonte estratégico para el desarrollo integral de los países de la región, no puede ignorarse ni menoscabarse la fuerte sensación de malestar y desencanto en las sociedades de los países de la región en torno a la situación actual del proceso de integración. No cabe duda que esta sensación se amplifica en el seno de las sociedades de los Estados más pequeños.

En esa dirección, deviene como interrogante clave si ¿pueden encontrarse evidencias consistentes sobre visiones estratégicas convergentes en la región? A juicio de Caetano, cabe el señalamiento de fuertes dudas al respecto. Abona esa visión la constatación acerca de que los partidos políticos, sobre todo los "progresistas", son más integracionistas en la oposición que en el gobierno. Asimismo, al tiempo que persiste la fuerza de los intereses de los estados nacionales, se ponen de manifiesto de manera especial fuertes recelos en los gobiernos de la región en torno a apuestas de signo supranacional.

Se señala no obstante, entre múltiples razones, que aún en el contexto adverso la implementación del PARLASUR ha de aportar más y mejor gobernabilidad.

Siguiendo esta línea argumental cabe coincidir con diversos autores quienes se han preguntado acerca de cuál es entonces, la contribución de los parlamentos latinoamericanos a la gobernabilidad, entendiéndola en su aspecto prospectivo, en su relación con la formulación de políticas públicas en la región.

Bonvecchi-Rodríguez (2010) afirman que la contribución de los parlamentos es inversamente proporcional a su poder político e institucional. En principio y en la generalidad de los análisis se sostiene que parlamentos poderosos han aprobado reformas mientras que parlamentos débiles las han bloqueado.

Los escenarios en los cuales se desarrollan las posibles contribuciones están impactados por los cambios en la estructura de los partidos y en los patrones de competencia política de los sistemas partidarios que alteran los incentivos de carrera política y de desempeño legislativo de los parlamentarios.

Estos incentivos cambiantes de los legisladores tienden a modificar sus preferencias de política y sus formas de participación en los procesos de reformas.

Así, a menor integración partidaria, menores incentivos para 
proponer reformas estructurales de alcance general. Contrario imperio, a mayor integración partidaria, mayores incentivos para limitar la autoridad del Ejecutivo y para hacer reformas estructurales de alcance general.

Sin embargo, al someter los modelos de las legislaturas suramericanas a la tipología de Cox-Morgenstern (2002: 453-455), se demostró que no existe la pretendida relación directa como se afirmara previamente. Tomando el caso de algunas experiencias históricas, por ejemplo la Argentina en el período de 1989-1999 (BonvecchiRodríguez, 2009) puede verse como el partido del gobierno en el Congreso aprobó más privatizaciones por ley cuando estaba altamente nacionalizado e integrado, y en cambio bloqueó más privatizaciones -y forzó al Ejecutivo a aprobarlas por decreto- cuando su integración política y su nacionalización partidaria disminuyeron.

El estudio que referenciamos concluye en que la influencia de los parlamentos en la toma de decisiones generales y de relevancia no depende necesariamente de sus poderes institucionales ni del tipo de política pública en discusión.

Las variaciones en la estructura del sistema partidario y la nacionalización de los partidos explican mejor los cambios en el tipo de políticas aprobadas por el Congreso.

Como lo muestra la tipología de presidentes y asambleas de Cox y Morgenstern $(2002)^{1}$ los presidentes pueden promulgar políticas utilizando diferentes estrategias según el tipo de legislatura a la que se enfrentan En segundo lugar, una perspectiva estratégica resalta la desventaja de tratar la variable clave de apoyo legislativo a las iniciativas presidenciales como una variable exógena. Aunque Cox y Morgenstern siguen la práctica normal de considerar el número de bancas de legisladores que apoyan al presidente ya sea como un factor endógeno o como uno exógeno a su modelo, sí destacan lo que ellos llaman los poderes integrativos presidenciales, tal como el nombramiento de ministros que un presidente puede usar para involucrarse directamente en el proceso legislativo.

La influencia de los parlamentos en la formulación de políticas ocurre entonces en la tensión entre la representación de los ciudadanos y los incentivos y restricciones para la toma de decisiones que se derivan de la distribución del poder partidario entre los parlamentarios.

1 Tipologías legislativas en relación al Poder Ejecutivo: 1) Subordinada, 2) Parroquial, 3) Cooperativa y 4) Renuente. 
América Latina ha vivido un proceso de reconversión político y social, después de la época neoliberal de los años 90, y también de cambio en la manera de pensar respecto de los países que comparten su situación geográfica. De hecho, en los últimos cinco años, ocurrieron varias circunstancias de otros países, como en el caso de Bolivia, de Venezuela y Colombia, o lo de sucedido con Correa en Ecuador; que han motivado la intervención política de los mandatarios latinoamericanos.

El debate acerca del impacto de las relaciones entre el ejecutivo y el legislativo sobre la parálisis o dinámica gubernamental ciertamente no está cerrado.

Otros hallazgos describen un nuevo panorama de las democracias presidenciales de América Latina. Es notable que los sistemas presidenciales latinoamericanos, aunque muestran gran variación, ocupan una posición intermedia entre los sistemas presidenciales puros y los sistemas parlamentarios puros, y cuentan con presidentes proactivos y legislaturas reactivas que no son tan pasivas como algunos han temido (Cox y Morgenstern, 2002).

Asimismo, a los presidentes de América Latina ni les falta apoyo en la legislatura ni confrontan rutinariamente el problema del "bloqueo" gubernamental. Ciertamente, los presidentes rara vez se enfrentan a la oposición de la mayoría en la legislatura y con frecuencia pertenecen al partido que tiene una mayoría en la legislatura o encabezan una coalición mayoritaria. Pero aun los presidentes que encabezan gobiernos de minoría no se encuentran especialmente dispuestos a usar su poder de decreto. Finalmente, las democracias presidenciales tienen apenas un poco menos de éxito legislativo que las democracias parlamentarias. Por tanto, la diferencia entre las democracias presidenciales y las parlamentarias, entendidas en torno al hecho de que en las democracias presidenciales tanto el jefe del ejecutivo como los miembros de la legislatura son directamente electos por los ciudadanos y tienen un mandato de duración fijo, aparentemente no determina la habilidad del gobierno para legislar.

Cuando se aborda la problemática de los partidos políticos, ha de considerarse su régimen específico, el sistema electoral, el sistema de gobierno -sea presidencialista o parlamentarista-. América Latina tiene una cultura de liderazgos fuertes, basada en un sistema presidencialista y en prácticas que tienen que ver con conducciones y referencias muy fuertemente unipersonales. ¿Por qué ocurre esto? (Cadesa, 2011).

Los liderazgos latinoamericanos, aún en el caso de los partidos 
que se definen de izquierda, y los liderazgos nacionales, son fuertemente personalistas porque no están representando una institución o un partido, sino que están representando algo mucho más abstracto que es la idea de construcción de la Nación de la mano de quien puede concretarlo según el imaginario popular.

Dadas las características configurantes del Parlamento del MERCOSUR, es de esperar que aún desarrolle el potencial de representatividad que contienen en ciernes. La expectativa se centra en que cuando esté funcionando con base ciudadana se conviertan en generadores de propuestas integracionistas, controlen el actuar de los ejecutivos, velen por la continuidad democrática y contribuyan a una mejor calidad democrática en la región. Será el momento entonces que abandonen su naturaleza intergubernamental y den un paso hacia la supranacionalidad de sus normas.

\section{Pendientes del MERCOSUR}

En el contexto descripto el bloque debe abordar prioritariamente los siguientes puntos definidos en su agenda:

\section{Revisión del Protocolo de Ushuaia -Cláusula Democrática}

La cuestión de Paraguay reveló las discordancias en los criterios de aplicación del Protocolo y ha dejado pendiente la situación de Venezuela al momento del reingreso de Paraguay al finalizar su sanción.

\section{Plan Estratégico de Acción Social del MERCOSUR (Decisión $12 / 11$ y $67 / 10)$}

Se ha definido el Eje 10: Implementación y financiamiento de políticas sociales. Se ha creado el Instituto Social del MERCOSUR quien deberá llevar a cabo el Plan Estratégico de Acción Social.

\section{Estatuto de la Ciudadanía del MERCOSUR (Decisiones 63 y 64/10)}

Esta norma implica la adopción de la Política de Libre Circulación y la de Igualdad de acceso a los derechos sociales, culturales y económicos. Asimismo queda pendiente la implementación de la Igualdad de acceso al trabajo, la salud y la educación. Se ha explicitado el "Plan de acción a 10 años" con el objetivo de llegar a los 30 años del MERCOSUR con este aspecto consolidado. 
Programa de Consolidación de la Unión Aduanera (Decisión $56 / 10)$

Su implementación implicará la Coordinación de políticas macroeconómicas (art. 58). La puesta en funcionamiento de nuevas instituciones como el Grupo de Cooperación Internacional (Dec. 10/12), el Grupo de Relacionamiento Externo -GRELEX-. Se han definido -asimismo- "Mecanismos de vinculación política, comercial o cooperación con terceros países” que habrán de ser puestos en marcha.

\section{Perfil del Alto Representante General del MERCOSUR (Dec. $63 / 10)$}

Dado el breve tiempo transcurrido desde la creación de este organismo político, se espera se perfile con sus próximas intervenciones y desarrollos que demostrarán el modo en que se concretarán sus facultades y alcances.

Asimismo ha de sumarse el necesario impulso con el que deberá contar la consolidación del Parlamento del MERCOSUR que representa una referencia política simbólica. La falta de legitimidad política del proceso de integración MERCOSUR se adjudica a la necesidad de respuesta de una demanda de mayor representatitividad de la ciudadanía en forma genérica (Gajate, 2012).

Priorizar elárea político - social de la integración implica garantizar el orden democrático y en la segunda fortalecer la participación social. Ambos aspectos contribuyen directamente a la construcción de una ciudadanía MERCOSUR que tendrá por fin legitimar el proceso como resultado final de reconocer a los pueblos de los Estados parte como protagonistas y destinatarios de los esfuerzos integrativos.

Nos preguntamos si el bloque se encuentra en condiciones de abordar su ambiciosa agenda jurídico-política. Los interrogantes claves se expresan en las siguientes preguntas: ¿Quién ha de liderar este proceso? ¿Qué instituciones se han creado para propender al necesario proceso de concertación social y sectorial? ¿Cómo se implementa y se implementará el diálogo político más allá de los mandatarios ejecutivos? ¿Cómo se coordinan y se coordinarán políticas en los más altos niveles político y técnico? ¿Se está posibilitando la necesaria participación social que legitime las decisiones tomadas?

Nos cuestionamos acerca de si basta con la creación del Parlamento del MERCOSUR, el Foro de Concertación Política y el 
Agenda jurídico-política del MERCOSUR. Tendencias. Rita Gajate

Alto Representante del MERCOSUR para evolucionar en la dimensión político-jurídica de este proceso de integración.

Para dar respuesta a estos interrogantes indudablemente deberá priorizarse el rol que cumple el Parlamento y su transformación, en la construcción de la ciudadanía del MERCOSUR, en la coordinación de políticas multinivel y en la destinación de fondos que provienen del FOCEM -Fondo de Convergencia Estructural del MERCOSUR- para sustentar los desarrollos enunciados.

\section{Construcción de la ciudadanía en el MERCOSUR}

El MERCOSUR tiene un enorme desafío en dos planos. Por un lado, la incorporación de nuevos actores y por otro dotar de mayor democraticidad a su organización institucional (Vitar, 2011). En opinión del autor de referencia "lo que las cancillerías podían aportar, muy esforzada y meritoriamente, ya fue aportado; llegó la hora de que el MERCOSUR incorpore actores que lo dinamicen y que planteen otra dimensión de la integración. Lo dicho bien vale para la CAN y la UNASUR por presentar identidad en el proceso político en este aspecto.

En este sentido se torna fundamental la elección popular de los miembros del PARLASUR por el voto directo. Porque esos diputados que nos representarán en el nuevo Parlamento van a ser electos por regiones, por sectores geográficos, van a poder vincular el proceso de integración a los pueblos de esas regiones, van a tener que salir a hacer campañas, deberán plantear cuál es la importancia del MERCOSUR para la región y qué demandas de la región puede canalizar el MERCOSUR. Eso va a significar un gran dinamismo, "a mi juicio" (Vitar, 2011: 22), en la vida del bloque regional.

En la misma línea argumental otros autores (Puelles-Urzúa, 2011) señalan un doble déficit: el de la institucionalidad y el del conocimiento. La institucionalidad parlamentaria ciudadana puede ser uno de los mecanismos más aptos para intervenir sobre éstos déficits.

Sobre el de conocimiento, la cuestión podría ser obvia ya que una vez que la ciudadanía esté obligada a votar diputados para el MERCOSUR, por lo menos se preguntará de qué se trata. El éxito o el fracaso de esta dimensión va de la mano del rol que ocupe la participación política, del crédito o descrédito social del que goce o adolezca.

Hay quienes afirman (Pisani, 1995) que en el caso de la hoy Unión Europea, cuando la política había fracasado, un gran proyecto ocupó el 
espacio vacío de los partidos políticos: el proyecto de la construcción europea. Para que la UE se convierta en uno de esos grandes conjuntos con peso específico, fue preciso que la opinión pública, las fuerzas sociales y los agentes económicos se comprometan con el proyecto.

Se trataría entonces de gestar, a partir de la participación ciudadana un mayor compromiso con el proyecto de la integración en Sudamérica que arraigue con una intensidad creciente en la sociedad. La institucionalidad democrática ha de propender en esta línea.

Si la institucionalidad asegura la participación social, entonces se convertirá en un reaseguro del proceso. En este marco se hace necesario identificar las resistencias y los obstáculos. Estos están dados por tres “i” (Cafiero, 2011: 25): interpretaciones, intereses e ideologías. Lo que bloquea la densidad institucional de este tipo de procesos son las interpretaciones respecto de la utilidad o no del componente institucional o de las ideologías, sobre todo, por ciertos resabios de nacionalismos individualistas; o los intereses, es decir, aquellos que por una u otra razón no identifican la importancia de este proceso de integración, con un sentido utilitarista.

Se trata entonces de lograr un equilibrio de fuerzas e ideas en torno a una de mayor envergadura: si se alcanza a visualizar popularmente el beneficio de la participación en la toma de decisiones a través de los representantes electos en los parlamentos constituidos para legitimar las decisiones en la integración, ésta será más estable, duradera y democrática.

Para el logro de la pretendida armonía se hace imperioso un proceso de concientización y educación sobre los beneficios de la integración sudamericana.

\section{Conclusiones}

La construcción de una mayor y mejor gobernabilidad en el MERCOSUR depende de una combinación virtuosa de tres elementos centrales: a) el fortalecimiento político-institucional-democrático; b) el desarrollo socioeconómico y la integración social con la generación de políticas que satisfagan las necesidades básicas del conjunto de la población y c) la promoción de un clima internacional que privilegie la resolución pacífica y consensuada de conflictos (Coti, 2010).

La gobernabilidad ha sido tratada en una amplia dimensión relacionada con el binomio legitimidad - eficacia con la que los 
gobernantes gozan del reconocimiento de la ciudadanía. Este elemento se alimenta en el hecho de que las promesas manifestadas se cumplan. Situación que fundamenta la confianza popular en las políticas públicas emprendidas.

La eficacia pretendida redunda en mayor legitimidad y mejor gobernabilidad. Ambas variables se implican y condicionan mutuamente. Relacionar la gobernabilidad con convivencia democrática pone de relevancia un elemento que parecería oculto: el diálogo entre los poderes del Estado. Esta dinámica interna de los Estados partícipes en los proceso de integración replica a escala sudamericana. Los acercamientos y búsqueda de acuerdos deben concretarse no solamente entre gobernantes y gobernados sino que han de representar una saludable convivencia democrática de relaciones múltiples entre los diversos grupos actores del proceso. $10)$ :

Se ha afirmado en precedentes investigaciones (Mellado, 2010:

Hasta ahora en la integración sudamericana la participación de los actores sociales ha sido mínima y por lo general ha tenido fines tendientes a la legitimación del proyecto. Por ello es que nos enfrentamos a procesos a que "van de arriba hacia abajo". Ello se ve facilitado por la inexistencia de una institucionalidad regional desarrollada y efectiva, con normativas y procedimientos democráticos claramente delineados que garanticen participación y derechos a la ciudadanía y en segundo lugar, por la tendencia de los gobiernos a reducir la actuación y el protagonismo de las instituciones para asumir ellos mismos, mediante el proceso de Cumbres Presidenciales, la conducción. Todo lo anterior se ha reducido en una errónea percepción sobre la cesión de competencias a favor de un marco institucional supranacional que debilitaría aún más la capacidad política de los procesos de integración.

De lo analizado surge que la mayor representatividad con base ciudadana y popular reviste en este marco un rol sustancial. Por ende el rol que el Parlamento del MERCOSUR ha de desempeñar no puede minimizarse. Se hace imperiosa para el parlamento creado su constitución con base ciudadana. Para los estados involucrados la adecuación de sus normativas electorales para proceder a la concreta elección de parlamentarios.

Vale como ejemplo lo sucedido en el parlamento de la CAN que se encuentra más adelantado en este marco, no obstante aún restan 
elecciones populares para su configuración. El MERCOSUR aún no ha concretado este proceso de transformación. Paraguay sí ha procedido a la elección popular de sus escaños. Argentina debía haberlo hecho en octubre de 2011 y no lo hizo.

El bloque aún presenta debilidades jurídico-institucionales tales como la preeminencia de las decisiones de los ejecutivos por sobre los parlamentos, déficit de representación que podría conducir a adolescencias de legitimación; no obstante se destaca como fortaleza la voluntad política sostenida durante estos 23 años de camino y la búsqueda de consensos para la construcción y avance del MERCOSUR. El cambio de tendencia desde lo estrictamente comercial hacia lo político social deberá acompañarse de una mayor, sostenida y consistente construcción de una institucionalidad que dé cabida a los protagonistas del proceso: los ciudadanos.

Finalmente creemos que concreción de la representatividad ciudadana anunciada para el PARLASUR será el primer paso en la dirección señalada no obstante no conducirá a una mejor gobernabilidad si no se emprende un proceso de concientización social sobre dicha participación y se reviste a las decisiones de parlamentos de carácter vinculante en principio y de aplicación directa de su normativa en un futuro no tan lejano.

Queda por observar la construcción política a que dé lugar este proceso de conformación eleccionaria de los parlamentos. Un sano equilibrio de poderes implicaría el progreso hacia esquemas de integración con menor peso presidencialista y una mayor gravitación parlamentaria implicando la incorporación en el sistema decisorio de la deseada representación social.

\section{Referencias bibliográficas}

ALOP (2011) MERCOSUR 20 años. Elementos para un balance político del bloque regional. Relaciones Unión Europea-MERCOSUR: reflexiones desde la sociedad civil. México D.F. -Montevideo: ALOP-CLAEH. Disponible en: <http:// www.alop.org.mx/sites/default/files/LibroALOP.pdf > .

ALVARADO Carolina (2011) "La Elección Directa de Parlamentarios Andinos", Via Inveniendi Et Iudicandi 6 (2), juliodiciembre [online] disponible en: <http://viei.usta.edu.co/index. php?option=com_content \&view $=$ article $\& i d=53:$ la-eleccion-directade-parlamentarios-andinos \&catid $=46$ : decima-edicion-reflexiones - 
academicas\&Itemid $=133>$.

(2011a). "La importancia social y política del Parlamento Andino", en: Via Inveniendi Et Iudicandi 6 (2), julio-diciembre [online] disponible en: <http://viei.usta.edu.co/index.php?option=com content\&view =article\&id=105:la-importancia-social-y-politica-delparlamento-andino\&catid $=58$ :decimo-primera\&Itemid $=146>$.

ARROSA SOARES Susana (2011) "Balance y perspectivas del MERCOSUR cultural: 20 años de existencia”. En BRICEÑO RUIZ José El MERCOSUR y las complejidades de la integración regional. Buenos Aires: TESEO, p. 301-319.

BAUMANN Renato (2011) "El MERCOSUR a los veinte años. Una evaluación económica". En BRICEÑO RUIZ José El MERCOSUR y las complejidades de la integración regional. Buenos Aires: TESEO, p. 165201.

BILBAO Luis (2000) "Brasil tentado por una opción sudamericana”. En Le Monde Diplomatique, año II, n 13.

BONVECCHI Alejandro, RODRIGUEZ Jesús (2009) El papel de los Parlamentos latinoamericanos en el proceso de reformas de política pública. Disponible en: <http://www.cepal.org/de/agenda/5/39285/ Alejandro_Bonvecchi.pdf $>$.

BIZZOZERO Lincoln (2011) “Los primeros veinte años del MERCOSUR: del Programa de Liberación Comercial al Plan Estratégico de Acción Social". En Densidades (6), página 23-34.

BIZZOZERO Lincoln(2011a) "Uruguay en el recorrido del MERCOSUR: llave geopolítica de la región”. En BRICEÑO RUIZ José El MERCOSUR y las complejidades de la integración regional. Buenos Aires: TESEO, pág. 385-409.

BIZZOZERO Lincoln (2001). "Los primeros diez años del Mercosur. Repensando los pilares y las aristas de la construcción". En Cuadernos del SELA (62), mayo-agosto, pág. 177-199.

BOTTO Mercedes (coord) (2011) MERCOSUR, ¿para qué sirve? Claves para el debate sobre los alcances de la integración. Buenos Aires: FLACSOIDEP.

CADESA Gustavo (2011) en: Jornada Sistemas Políticos e Integración 
Regional. Parlamento del MERCOSUR - DELEGACIÓN ARGENTINA. Auspiciada por la Maestría en Integración Latinoamericana de la Universidad de Tres de Febrero y la conferencia Permanente de Partidos Políticos de América Latina y el Caribe (Coppal) y la Unidad de Enlace con el Parlamento del MERCOSUR y la Honorable Cámara de Diputados de la Nación. Versión taquigráfica. 12 de mayo.

CAETANO Gerardo (2011) MERCOSUR: 20 años. Montevideo, CEFIRGIZ- Fundación Ebert, Somos MERCOSUR.

CAETANO Gerardo (2006) "Parlamento Regional y Sociedad Civil en el proceso de Integración. ¿Una nueva oportunidad para el MERCOSUR?, en: Análisis y preguntas, diciembre.

CAFIERO Fernando (2011) en: Jornada Sistemas Políticos e Integración Regional. Parlamento del MERCOSUR - DELEGACIÓN ARGENTINA. Auspiciada por la Maestría en Integración Latinoamericana de la Universidad de Tres de Febrero y la conferencia Permanente de Partidos Políticos de América Latina y el Caribe (Coppal) y la Unidad de Enlace con el Parlamento del MERCOSUR y la Honorable Cámara de Diputados de la Nación. Versión taquigráfica. 12 de mayo.

CASTLES Stephen (2000) "Migración Internacional a comienzos del siglo XXI: tendencias y problemas mundiales" en: Revista Internacional de Ciencias Sociales (165), septiembre, p.17-32.

CERRONI Umberto (1972) “Desilusión, placer y emancipación”. En: La libertad de los modernos. Barcelona: Ed. Martínez Roca, pág. 19.

CORDOBA Arnaldo (1967) "Sociedad y Estado en el mundo moderno". En: Ciencias Políticas y Sociales, año XII(50), p. 463 y 464.

COSTA LIMA Marcos (2011) "Democratizar para integrar: las dificultades y las posibilidades de participación social en el MERCOSUR". En: BRICENO RUIZ José El MERCOSUR y las complejidades de la integración regional. Buenos Aires: TESEO, p. 225-269.

COTI Otilia Lux (2010) "Gobernabilidad y pueblos indígenas", en Gobernabilidad, trabajo y convivencia democrática América Latina. San José de Costa Rica: AECID - FLACSO.

COX Gary W., MORGENSTERN Scott (2002) "Latin America's Reactive Assemblies and Proactive Presidents", en MORGENSTERN Scott y NACIF Benito (eds) Legislative Politics in Latin America. Cambridge 
University Press: Nueva York, pp. 446-468.

En: MUNCK Gerardo (2004), La política democrática en América Latina: contribuciones de una perspectiva institucional, vol. XI, núm. 2, 2do semestre.

CENTRAL DE TRABAJADORES DE LA ARGENTINA. SECRETARÍA DE RELACIONES INTERNACIONALES (2006) La institucionalidad del MERCOSUR: una reforma necesaria. Buenos Aires: Ediciones Debate Internacional. (Serie Integración Regional).

FOX Jonathan (2005) “Unpacking transnational citizenship”. En: Annual Review of Political Science, 8, p. 194.

FAYT Carlos (2008) Sufragio, Representación y Telepolítica. Buenos Aires: La Ley.

FLACSO (2009) El MERCOSUR estructural. Desafíos de la integración política, social y cultural. Jornada de Relaciones Internacionales. Publicación de conclusiones.

GAJATE Rita Marcela (2013) En MELLADO Noemí Beatriz (coord yedit) y FERNÁNDEZ SACCA Juan (coed). "Problemáticas del Regionalismo Latinoamericano en los inicios del Siglo XXI”. Capítulo II de autoría de Rita Gajate: Instituciones de los Procesos de Integración sudamericanos. Modelos y tendencias actuales: Págs. 55-74. Ed. Universidad Dr. José Matías Delgado, El Salvador. Publicación Internacional.

GAJATE Rita Marcela (2013) "Problemáticas del Regionalismo Latinoamericano en los inicios del Siglo XXI" En MELLADO Noemí Beatriz (coord y edit) y FERNÁNDEZ SACCA Juan (coed) Instituciones de los Procesos de Integración sudamericanos. Modelos y tendencias actuales. El Salvador: Ed. Universidad Dr. José Matías Delgado, p. 55-74.

GAJATE Rita Marcela (2010) "Los Parlamentos de la CAN y MERCOSUR: ¿Garantía de gobernabilidad para los bloques?”. En: Mellado Noemí (edit) Gobernabilidad e Instituciones en la Integración Regional. Córdoba: Ed. Lerner, p. 93-123.

GARNELO Vicente (1998) Evolución institucional y jurídica del MERCOSUR. Documento de Divulgación No 3. BID-INTAL.

GUIDO Emiliano (2013) "El tetris del MERCOSUR". En Realidad Económica. IADE - Instituto Argentino de Desarrollo Económico. 
Revista $\mathrm{N}^{\circ}$ 275. 17/07/13. Disponible en: <http://www.iade.org.ar/ modules/noticias/article.php?storyid=4710>

ITZIGSOHN José (2000) "Immigration and the boundaries of citizenship: the institutions of immigrants political transnationalism". En: International Migration Review, vol. 3, núm. 4, p. 1148.

KELSEN Hans (1965) Teoría general del Estado. México: Ed. Nacional: p. $99-120$.

MARTÍNEZ PUÑAL Antonio (2005) El sistema institucional del MERCOSUR: de la intergubernamentalidad hacia la supranacionalidad. Tórculo Edicions. Colección de Estudios Internacionales. Santiago de Compostela. España.

MELLADO Noemí (2011) "Estado, sociedad civil e integración. Hacia su rearticulación” En BRICEÑO RUIZ José El MERCOSUR y las complejidades de la integración regional. Buenos Aires: TESEO, p. 271300.

MELLADO Noemí B. (2010) Gobernabilidad e instituciones en la integración regional. Córdoba: Ed. Lerner.

MERCADO (2013) "La política tiñe la agenda del MERCOSUR". Mercado 20 julio 2013 [online] disponible en: <http://www.mercado. com.ar/notas/sin-categoria/8013070/la-poltica-tie-la-agenda-delmercosur- $>$.

MONTBRUN Alberto (2007) "Bases de representación legislativa y sistemas electorales en el derecho público provincial" En PEREZ GUILHOU Dardo (dir) Derecho público provincial y municipal volumen III. Buenos Aires: La Ley.

NOHLEN Dieter et al (comp) (2005) Tratado de Derecho Electoral comparado de América Latina. México: Fondo de Cultura Económica.

NOHLEN Dieter (1994) Sistemas Electorales y Partidos Políticos. México: Fondo de Cultura Económica.

PANTOJA MORÁN David (1988) "Ciencia Política y análisis jurídico”. En: Estudios en homenaje al Dr. Héctor Fix Zamudio en sus 30 años como investigador en Ciencias Jurídicas. México: UNAM. Instituto de Investigaciones Jurídicas, p. 549-562. 
Agenda jurídico-política del MERCOSUR. Tendencias. Rita Gajate

PÉREZ VICHICH Nora (1997) "MERCOSUR: la libertad de circulación de trabajadores en debate" En: Revista del Instituto de Relaciones Internacionales de la Universidad Nacional de La Plata, año 7(12).

PISANI Edgard (1995) "La Europa Política”, en: Revista de Coyuntura Económica, (1), p. 11-17.

PUELLES BENÍTEZ Manuel, URZÚA FRADERMAN Raúl (2011) "Educación, gobernabilidad democrática y gobernabilidad de Sistemas Educativos", en: Educación y gobernabilidad democrática. Revista Iberoamericana de Educación (12) [online] disponible en: <www.oei.es/ oeivirt/ric12a05.htm>.

RODRIGUEZ Tania Julieta (2009) "El MERCOSUR estructural. Desafíos de la integración política, social y cultural" En Las relaciones internacionales hoy: Jornada de Relaciones Internacionales. Publicación de conclusiones.

SONTHEIMER Kurt (1971) Ciencia política y teoría jurídica del Estado, Traducción de Luis Villagra. Buenos Aires: EUDEBA, p. 12-14.

SOSA Alberto (2011) "Menem y los Kirchner: continuidades y rupturas en el MERCOSUR" En BRICEÑO RUIZ José El MERCOSUR y las complejidades de la integración regional. Buenos Aires: TESEO, p. 355383.

UELTSCHI María Cristina (2003) "El MERCOSUR político" En: ARGENTINA. MINISTERIO DE RELACIONES EXTERIORES Aportes para el Debate. Buenos Aires: Cancilleria Argentina, p. 17-28.

VAILLANT Marcel (2011) "Brasil y sus tres vecinos del Sur. 2 décadas de integración en 7 dimensiones". Espectador Negocion.com [online] disponible en: $<$ http://www.espectadornegocios.com/especialmercosur_ core.php? $\mathrm{m}=\mathrm{amp} \& \mathrm{nw}=\mathrm{MzYxNQ}>$.

VÁZQUEZ Mariana (2002) “Sobre la dimensión parlamentaria de los procesos de integración regional. El MERCOSUR y la Unión Europea en perspectiva comparada a la luz de los desafíos del Área de Libre Comercio de las América", Revista de Ciencia Política, (5/6).

VIGEVANI Tullo, RAMANZINI Haroldo Jn. (2011) "El MERCOSUR y la política exterior brasileña”. En BRICEÑO RUIZ José El MERCOSUR $y$ las complejidades de la integración regional. Buenos Aires: TESEO, p. $321-363$. 
VILLAR Gabriel (2010) “Derecho y Ciencia Política”. En Revista Debates. Entrevistas, Año 1(1). [online] disponible en: <www.isnsc.com.ar>.

VITAR José (2011) en: Jornada Sistemas Políticos e Integración Regional. Parlamento del MERCOSUR - DELEGACIÓN ARGENTINA. Auspiciada por la Maestría en Integración Latinoamericana de la Universidad de Tres de Febrero y la conferencia Permanente de Partidos Políticos de América Latina y el Caribe (Coppal) y la Unidad de Enlace con el Parlamento del MERCOSUR y la Honorable Cámara de Diputados de la Nación. Versión taquigráfica. 12 de mayo.

TELAM (2013) Cumbre del Mercosur: Uruguay analiza proponer un arancel externo común para China. [online] disponible en: <http://www. telam.com.ar/notas/201307/24315-uruguay-propondria-un-arancelexterno-comun-para-china-en-la-cumbre-del-mercosur.html $>$. 